\title{
A PRELIMINARY QUALITY ANALYSIS OF THE CLIMATE CHANGE INITIATIVE LAND COVER PRODUCTS FOR CONTINENTAL PORTUGAL
}

\author{
C. C. Fonte ${ }^{1,2, *}$, L. See ${ }^{3}$, M. Lesiv ${ }^{3}$, S. Fritz ${ }^{3}$ \\ ${ }^{1}$ Department of Mathematics, University of Coimbra, Coimbra, Portugal - cfonte@mat.uc.pt \\ ${ }^{2}$ Institute for Systems Engineering and Computers at Coimbra (INESCC), Coimbra, Portugal \\ ${ }^{3}$ International Institute for Applied Systems Analysis, Laxenburg, Austria - (see, lesiv, fritz)@iiasa.ac.at
}

Commission IV, WG IV/3

KEY WORDS: Climate Change Initiative, Land Cover, Change detection, Quality, Omission errors, Commission errors

\begin{abstract}
:
The aim of this paper is to perform a preliminary analysis of the compatibility and quality of the available time series of land cover data available for continental Portugal, in particular, Climate Change Initiative Land Cover maps, which are available annually from 1992 to 2015; CORINE Land Cover and the Urban Atlas for 2006 and 2012; and the Portuguese Carta de Ocupação do Solo for 2007 and 2010. Changes were first identified per product between the different data sets for consecutive dates and then a comparison was made between products. This was followed by validation of two study areas using the COS and UA as reference products. The results show that increases in urbanization are visible in all pairs of products but that the amount of change varies. Moreover, some changes are not in the same direction but may be attributable to classes with small areas and the coarser resolution of the CCI LC maps compared to the other products. The CCI LC maps also overestimate the forest/natural vegetation class by $11-13 \%$, which is also the largest class in Portugal.
\end{abstract}

\section{INTRODUCTION}

Land Cover (LC) is an Essential Climate Variable and an input to many applications from biodiversity monitoring to ecosystem accounting. Land use is the function associated with the land or the way in which the land is used. LC, and to a lesser extent land use, are frequently mapped using remote sensing, often for certain points in time or for a certain year. More recently, the Climate Change Initiative (CCI) produced a global annual and consistent time series of LC maps from 1992 to 2015 (Santoro et al. 2017) so that LC change over time could be monitored. However, there has been little attempt so far to validate this new generation of LC change products. Hence, the aim of this paper is to assess the quality of the available time series of land cover data available for continental Portugal, in particular, CCI LC maps, which are available annually from 1992 to 2015; CORINE Land Cover (CLC) and the Urban Atlas (UA) for 2006 and 2012; and the Portuguese Carta de Ocupação do Solo (COS) for 2010 and 2015, produced by the Portuguese National Mapping Agency. Changes were first identified between the different data sets for consecutive dates and then compared, followed by validation of two study areas using COS and UA as reference products.

\section{DATA AND METHODS}

\subsection{Data}

Several LC data sets are used in this study. The first is the CCI LC time series product at a $300 \mathrm{~m}$ resolution, available annually from 1992 to 2015 (Santoro et al. 2017), which are intended to be consistent over time. Hence a multi-temporal, multi-sensor approach is used. A unique baseline LC map was first generated using data from the MERIS archive from 2003 to 2012. Changes were then detected using imagery time series from AVHRR,
SPOT-VGT and PROBA-V. Finally, the baseline map was updated to produce the 24 annual LC maps from 1992 to 2015.

The second is CLC for the years 2006 and 2012, where these products have been generated as part of the Copernicus Land Monitoring Service (Buettner 2014). The CLC product is intended to be a consistent, comparable, pan-European land cover product containing 44 land cover classes at the most detailed level. The minimum mapping unit (MMU) for CLC is $0.25 \mathrm{~km}^{2}$ for polygons with minimum width of $100 \mathrm{~m}$ for linear features. The product has a positional accuracy of $100 \mathrm{~m}$ and the overall thematic accuracy is greater than $85 \%$. Generated in both vector and raster format with $100 \mathrm{~m}$ and $250 \mathrm{~m}$ resolutions.

The third is the UA product for 2006 and 2012 (EEA 2011), which has also been generated as part of the Copernicus Land Monitoring Service. Similar to the CLC, the idea behind the UA was to produce a harmonized urban product so that cities across the EU could be compared. In 2006, the UA is available for 305 cities while 695 cities are available in 2012. In urban areas, the MMU is $0.0025 \mathrm{~km}^{2}$ and in rural areas it is 1 ha. The minimum width of linear elements is the same as CLC while the positional accuracy is $\pm 5 \mathrm{~m}$.

The final products used are the Portuguese Carta de Ocupação do Solo (COS) for 2007 and 2010, which have been produced by the Portuguese National Mapping Agency (Direção Geral do Território - DGT) by visual interpretation of very high resolution orthorectified aerial images. This product has been created since 1995, and is available for the years 1995, 2007, 2010 and 2015. In this preliminary analysis, only the products of 2010 and 2015 were used. The nomenclature used in COS 2010 and 2015 has, respectively, 225 and 48 classes at the most detailed level $\left(5^{\text {th }}\right.$ level). However, level 1 includes the same classes in both products. The (MMU) for COS is $1 \mathrm{ha}\left(0.01 \mathrm{~km}^{2}\right)$ for polygons. The minimum distance between lines and the smallest polygon width is $20 \mathrm{~m}$. The overall thematic accuracy is reported to be greater than $85 \%$, but for level 1 , it is reported to

\footnotetext{
* Corresponding author
} 
be $97 \%$ for COS 2010 and $96 \%$ for COS 2015 (Caetano et al. 2018). The product is available in vector format for NUTS II.

\subsection{Nomenclature harmonization}

To perform comparisons between the products, a harmonization of level 1 classes was done. Table 1 shows the level 1 nomenclature of the CCI LC and whether each class is present in the CLC LC for Portugal. Table 2 shows the level 1 nomenclature for CLC, UA (2006 and 2012) and COS.

\begin{tabular}{|c|c|c|}
\hline Code & Description & $\begin{array}{l}\text { In Portugal? } \\
(\mathrm{Y} / \mathrm{N})\end{array}$ \\
\hline 10 & Cropland, rainfed & $\mathrm{Y}$ \\
\hline 20 & Cropland, irrigated or post-flooding & Y \\
\hline 30 & $\begin{array}{l}\text { Mosaic cropland }(>50 \%) / \text { natural } \\
\text { vegetation (tree, shrub, herbaceous } \\
\text { cover) }(<50 \%)\end{array}$ & Y \\
\hline 40 & $\begin{array}{l}\text { Mosaic natural vegetation (tree, } \\
\text { shrub, herbaceous cover) }(>50 \%) / \\
\text { cropland }(<50 \%)\end{array}$ & Y \\
\hline 50 & $\begin{array}{l}\text { Tree cover, broadleaved, evergreen, } \\
\text { closed to open }(>15 \%)\end{array}$ & $\mathrm{N}$ \\
\hline 60 & $\begin{array}{l}\text { Tree cover, broadleaved, deciduous, } \\
\text { closed to open }(>15 \%)\end{array}$ & Y \\
\hline 70 & $\begin{array}{l}\text { Tree cover, needleleaved, evergreen, } \\
\text { closed to open }(>15 \%)\end{array}$ & Y \\
\hline 80 & $\begin{array}{l}\text { Tree cover, needleleaved, deciduous, } \\
\text { closed to open }(>15 \%)\end{array}$ & Y \\
\hline 90 & $\begin{array}{l}\text { Tree cover, mixed leaf type } \\
\text { (broadleaved and needleleaved) }\end{array}$ & Y \\
\hline 100 & $\begin{array}{l}\text { Mosaic tree and shrub }(>50 \%) / \\
\text { herbaceous cover }(<50 \%)\end{array}$ & Y \\
\hline 110 & $\begin{array}{l}\text { Mosaic herbaceous cover }(>50 \%) / \\
\text { tree and shrub }(<50 \%)\end{array}$ & Y \\
\hline 120 & Shrubland & $\mathrm{Y}$ \\
\hline 130 & Grassland & Y \\
\hline 140 & Lichens and mosses & $\mathrm{N}$ \\
\hline 150 & $\begin{array}{l}\text { Sparse vegetation (tree, shrub, } \\
\text { herbaceous cover) }(<15 \%)\end{array}$ & Y \\
\hline 160 & $\begin{array}{l}\text { Tree cover, flooded, fresh or brakish } \\
\text { water }\end{array}$ & $\mathrm{N}$ \\
\hline 170 & Tree cover, flooded, saline water & $\mathrm{N}$ \\
\hline 180 & $\begin{array}{l}\text { Shrub or herbaceous cover, flooded, } \\
\text { fresh/saline/brakish water }\end{array}$ & Y \\
\hline 190 & Urban areas & Y \\
\hline 200 & Bare areas & Y \\
\hline 210 & Water bodies & Y \\
\hline 220 & Permanent snow and ice & $\mathrm{N}$ \\
\hline
\end{tabular}

Table 1. Level 1 nomenclature of the CCI LC, and the classes present in the mainland Portuguese territory

\begin{tabular}{|l|l|}
\hline Code & \multicolumn{1}{|c|}{ Description } \\
\hline 1 & Artificial surfaces \\
2 & Agricultural areas \\
3 & Forest and (semi-)natural areas \\
4 (not used in UA 2006) & Wetlands \\
5 & Water \\
\hline
\end{tabular}

Table 2. Level 1 nomenclature of the CLC, UA and COS LC products

The harmonization was performed only for the classes existing for Portugal in CCI LC, as shown in Table 3. The harmonization of CCI LC classes of mixed land cover, which correspond to different classes in the nomenclature of Table 2 (classes 30, 40 and 110) was done considering the land cover corresponding to the class with the highest percentage. All subsequent analysis was undertaken using the level 1 nomenclature of CLC, UA (2012) and COS.

\begin{tabular}{|l|l|l|}
\hline $\begin{array}{l}\text { Codes (CLC, } \\
\text { UA, COS) }\end{array}$ & \multicolumn{1}{|c|}{ Description } & \multicolumn{1}{c|}{ CCI LC codes } \\
\hline 1 & Artificial surfaces & 190 \\
2 & Agricultural areas & $10,20,30$ \\
3 & Forest and (semi-) & $40,60,70,80,90,100$, \\
& natural areas & $110,120,130,150,200$ \\
4 & Wetlands & 180 \\
5 & Water & 210 \\
\hline
\end{tabular}

Table 3. Mapping between the nomenclatures of Tables 1 and 2

\subsection{Methodology}

The methodology used in this study includes three main steps: 1) Data pre-processing to enable product comparison; 2) Assessing change with CCI LC products; 3) Comparing change detection with CCI LC and other products (CLC and COS) for the whole Portuguese continental territory; 4) Accuracy assessment of CCI LC using the high resolution products, namely COS and UA for two study areas.

2.3.1 Data pre-processing: In order to be able to compare products, they were all converted to the projected reference system PT-TM06/ETRS89, resampling with the "nearest" operator. The pixel centroids of the CCI LC classes were then extracted, and the classes found in the other products (all available in vector format) were then associated to these points using a spatial join. This enabled the class in each product to be associated to each pixel centroid.

2.3.2 Change detection with CCI LC for continental Portugal: The LC change was assessed with the CCI LC maps of 2006, 2010, 2012 and 2015 using the harmonized nomenclature, both in terms of area and percentage.

2.3.3 Compare existing products and calculate change: After the LC products were harmonized by LC type (see section 2.2 ), the LC products were compared and the changes were extracted from existing products that corresponded to similar dates, i.e., CLC for 2006 and 2012 (UA could not be used at this step because it is not available for the whole territory), and COS for 2010 and 2015.

2.3.4 Validate the land cover change: To validate the CCI LC maps and the detected changes, in this preliminary work the high-resolution products $\mathrm{COS}$ and UA were used as reference data. This was done on one hand because for level 1 nomenclature these products have very high accuracy (always larger than $90 \%$ ), and on the other hand because these products have a level of detail much higher than CCI LC, which for this analysis can be considered to be very close to reality. As UA is only available for some regions, two study areas with different characteristics (described in section 2.4) were selected where UA is available. Contingency tables were then created using the centroids of all pixels (corresponding to a systematic sample) and Commission Errors (CE), Omission Errors (OE) and the Overall Accuracy (OA) were computed considering the high-resolution products as reference data. The impact of the identified changes on the quantification of real LC change in those areas was then analysed. 


\subsection{Study areas}

Two study areas were selected that have different characteristics. Study area A includes the city of Coimbra, as well as agricultural fields, some regions with forest as well as discontinues urban areas (see Figure 1). Study area B includes mainly forested regions, with some agricultural areas and a few small villages (see Figure 2).

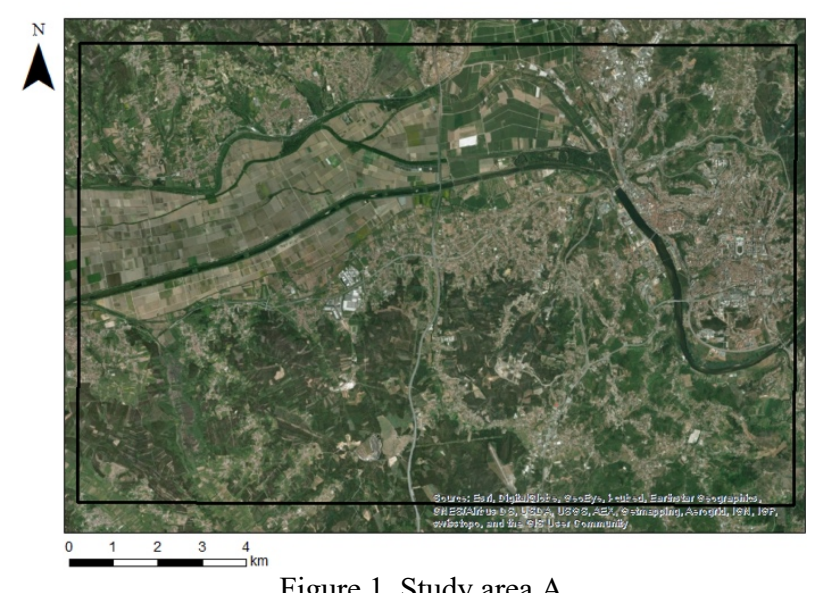

Figure 1. Study area A

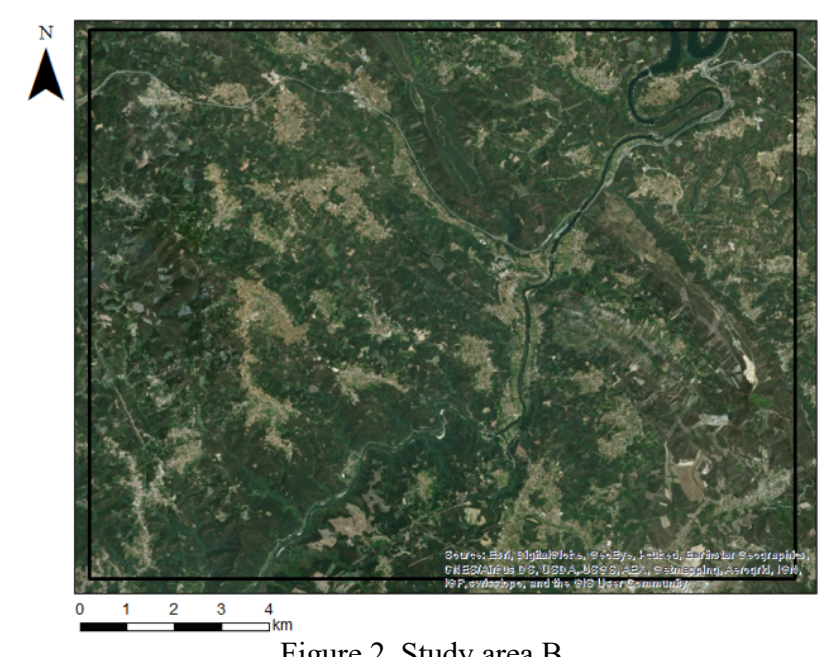

Figure 2. Study area B

\section{RESULTS}

The following subsections present the results from the analyses performed as outlined in section 2.3.

\subsection{Change detection with CCI LC}

Table 4 shows the area of each class in the CCI LC maps of 2006, 2010, 2012 and 2015. Table 5 shows the differences obtained between the products for consecutive years in the time series considered here. It can be seen that the area of class 1 (Artificial surfaces) always increases with time, and the area of classes 2 (Agricultural areas) and 3 (Forest and (semi-) natural areas) always decreases. The area occupied by classes 4 (Wetlands) and 5 (Water) remain more or less stable over time (Tables 4 and 5).

Similar results were obtained per district, where most identified changes occurred in class 1 .

\begin{tabular}{|l|c|c|c|c|}
\hline Classes & 2006 & 2010 & 2012 & 2015 \\
\hline 1 & 1930 & 2227 & 2369 & 2646 \\
2 & 32259 & 32100 & 32012 & 31831 \\
3 & 53583 & 53444 & 53389 & 53289 \\
4 & 163 & 164 & 164 & 166 \\
5 & 1188 & 1190 & 1190 & 1191 \\
\hline
\end{tabular}

Table 4. Class areas in $\mathrm{km}^{2}$ of CCI LC maps for years 2006, 2010, 2012 and 1015

\begin{tabular}{|l|c|c|c|c|c|c|}
\hline \multirow{2}{*}{ Classes } & \multicolumn{2}{|c|}{$2010-2006$} & \multicolumn{2}{c|}{$2012-2010$} & \multicolumn{2}{c|}{$2015-2012$} \\
\cline { 2 - 7 } & $\mathrm{km}^{2}$ & $\%$ & $\mathrm{~km}^{2}$ & $\%$ & $\mathrm{~km}^{2}$ & $\%$ \\
\hline 1 & 297 & 15.4 & 142 & 6.4 & 277 & 11.7 \\
2 & -159 & -0.5 & -88 & -0.3 & -181 & -0.6 \\
3 & -139 & -0.3 & -55 & -0.1 & -100 & -0.2 \\
4 & 1 & 0.6 & 0 & 0.0 & 2 & 1.2 \\
5 & 2 & 0.2 & 0 & 0.0 & 1 & 0.1 \\
\hline
\end{tabular}

Table 5. Differences between the areas occupied by each class in consecutive years of the time series considered here, in $\mathrm{km}^{2}$ and percentage

\subsection{Comparison of CCI LC with other products}

A comparison of the land cover classes obtained with the CCI LC products and the CLC was made for the whole country for the years 2006 and 2012, and with the COS for 2010 and 2015.

Figures 3 and Figure 4 show, respectively, the CCI LC and the CLC for 2012. A visual analysis of these figures shows that class 3 occupies more area in CCI LC than in CLC, and the opposite occurs with class 2 . Regarding class 1 , the urban area of Oporto (main city in the north of the country) is more compact in $\mathrm{CCI}$ LC than in CLC, while smaller urban areas away from the main urban areas area smaller in CCI LC than in CLC or even or inexistent.

Table 6 shows the areas obtained per class for both years while Table 7 shows the differences between the two years for each product.

\begin{tabular}{|l|c|c|c|c|}
\hline \multirow{2}{*}{ Classes } & \multicolumn{2}{|c|}{2006} & \multicolumn{2}{c|}{2012} \\
\cline { 2 - 5 } & CCI LC & CLC & CCI LC & CLC \\
\hline 1 & 1930 & 3096 & 2369 & 3380 \\
2 & 32259 & 42019 & 32012 & 42715 \\
3 & 53583 & 42607 & 53389 & 41556 \\
4 & 163 & 289 & 164 & 303 \\
5 & 1188 & 1106 & 1190 & 1163 \\
\hline
\end{tabular}

Table 6. Areas in $\mathrm{km}^{2}$ per class for the CCI LC and the CLC for years 2006 and 2012

\begin{tabular}{|l|c|c|c|c|}
\hline \multirow{2}{*}{ Classes } & \multicolumn{2}{|c|}{ CCI LC (2012-2006) } & \multicolumn{2}{c|}{ CLC (2012-2006) } \\
\cline { 2 - 5 } & $\mathrm{km}^{2}$ & $\%$ & $\mathrm{~km}^{2}$ & $\%$ \\
\hline 1 & 439 & $22.7 \%$ & 284 & $9.2 \%$ \\
2 & -247 & $-0.8 \%$ & 696 & $1.7 \%$ \\
3 & -194 & $-0.4 \%$ & -1051 & $-2.5 \%$ \\
4 & 1 & $0.6 \%$ & 14 & $4.8 \%$ \\
5 & 2 & $0.2 \%$ & 57 & $5.2 \%$ \\
\hline
\end{tabular}

Table 7. Area differences per class between 2012 and 2006 for the CCI LC and the CLC, in $\mathrm{km}^{2}$ and percentage 


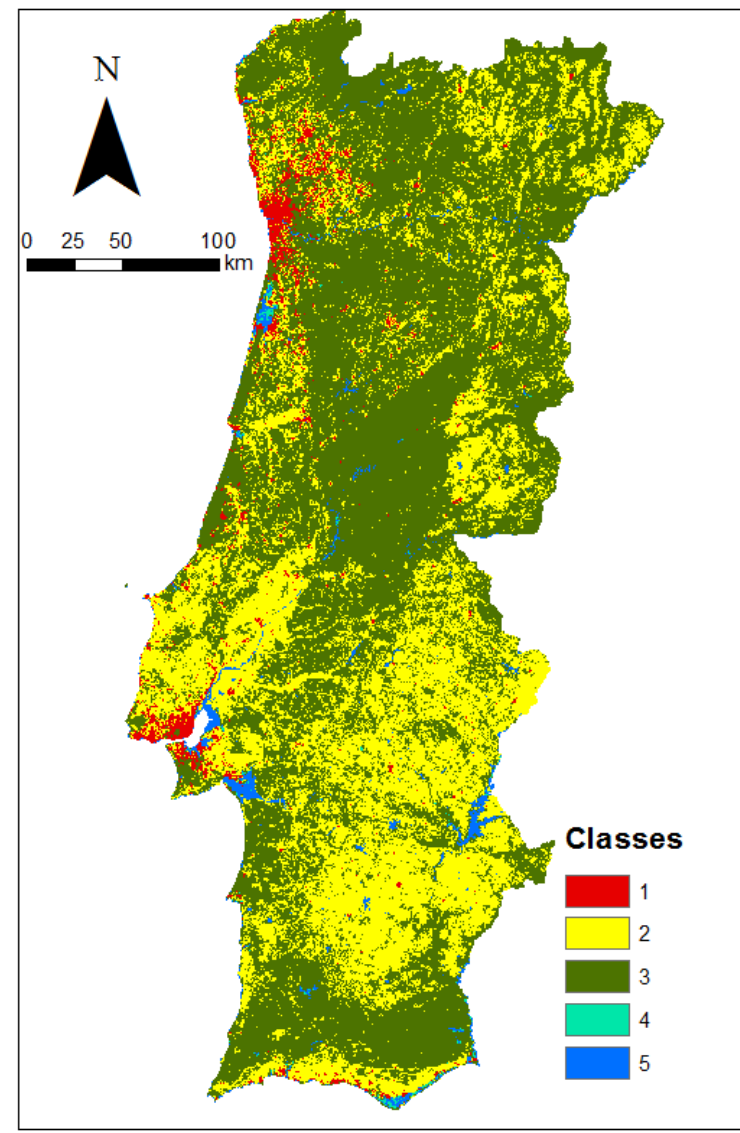

Figure 3. CCI LC of Portugal for 2012 with the harmonized nomenclature

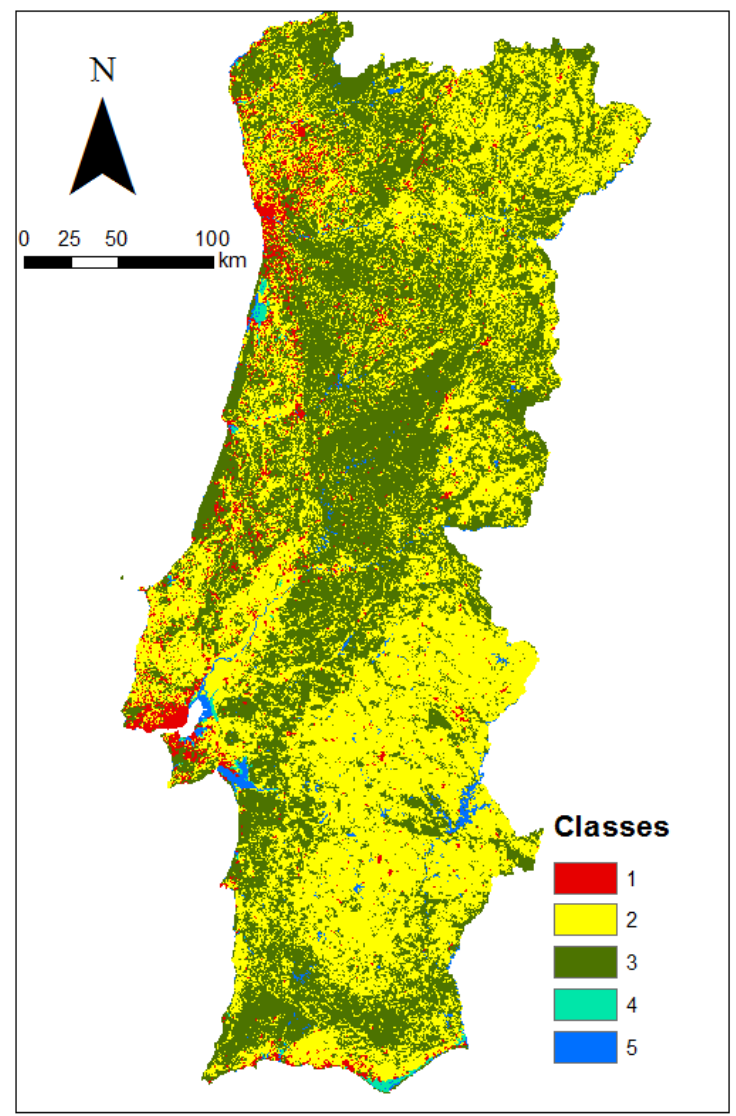

Figure 4. CLC of Portugal for 2012 with the level 1 nomenclature

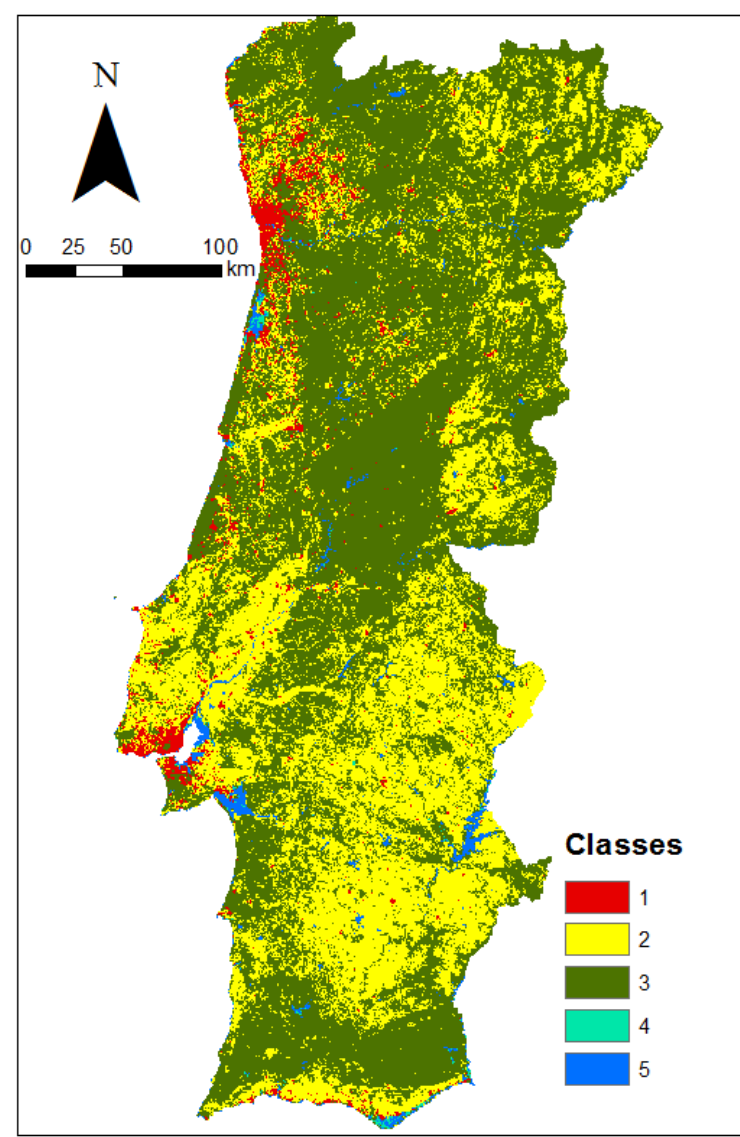

Figure 5. CCI LC of Portugal for 2015 with the harmonized nomenclature

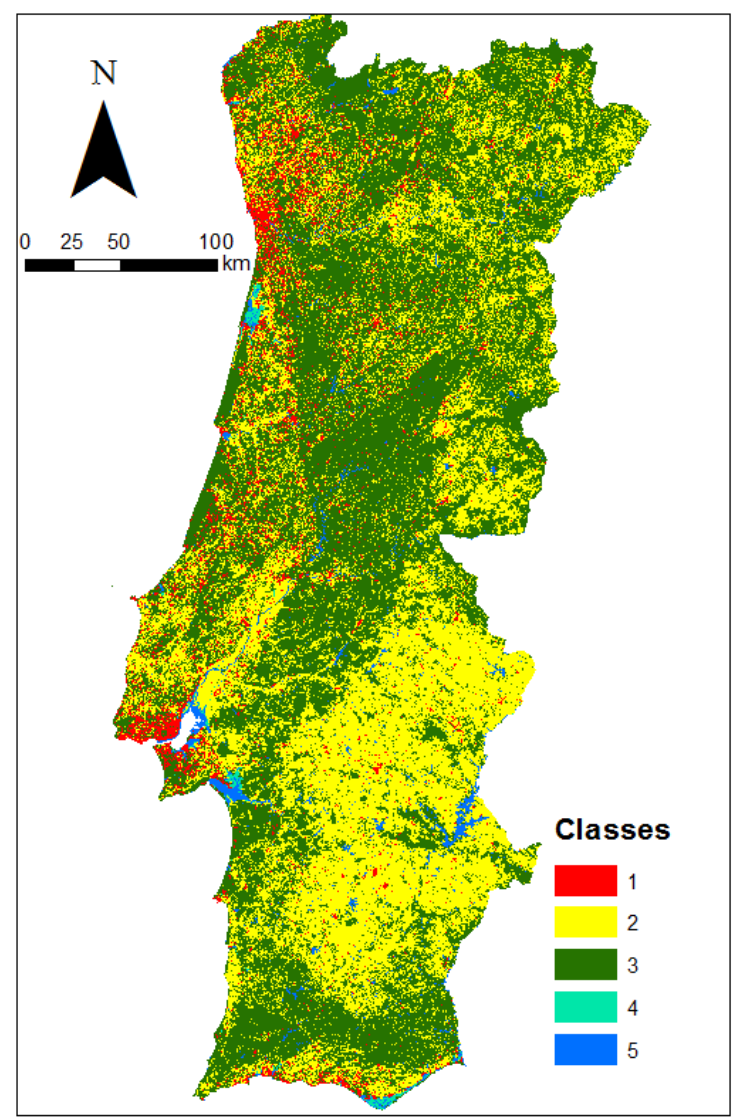

Figure 6. COS of Portugal for 2015 with the level 1 nomenclature 
The order of magnitude of the land cover differences estimated within the same product for 2006 and 2012 are similar (see Table 6), which shows consistency in the results obtained for each product for different years. The results in Table 7 show an increase of $439 \mathrm{~km}^{2}$ for class 1 with CCI LC (corresponding to $22.7 \%$ ), while with CLC there was only an increase of $284 \mathrm{~km}^{2}$ (corresponding to $9.2 \%$ ). However, the regions classified as class 1 in CLC are larger in both 2006 and 2012 (Table 6). The CCI LC estimates a decrease in class 2 and CLC an increase in this class. Regarding class 3 , both products estimate a decrease between 2006 and 2012; but CCI LC only estimates a decrease of $194 \mathrm{~km}^{2}(-0.4 \%)$ while CLC estimates a decrease of $1051 \mathrm{~km}^{2}$ (corresponding to $-2.5 \%$ ).

Table 8 shows the differences obtained for area change in each class when estimated from CCI LC and CLC. It can be seen that the larger differences are obtained for classes 1 and 4, which for 2006 , differ, respectively, by $60.4 \%$ and $77.3 \%$, while for 2012 , they differ, respectively, by $42.7 \%$ and $84.8 \%$. However, as class 4 only occupies small areas (see Table 6), these large differences in percentage correspond, in fact, to relatively small area differences.

\begin{tabular}{|l|c|c|c|c|}
\hline \multirow{3}{*}{ Classes } & \multicolumn{2}{|c|}{$\begin{array}{c}\text { CLC-CCI LC } \\
(2006)\end{array}$} & \multicolumn{2}{c|}{$\begin{array}{c}\text { CLC-CCI LC } \\
\text { (2012) }\end{array}$} \\
\cline { 2 - 5 } & $\mathrm{km}^{2}$ & $\%$ & $\mathrm{~km}^{2}$ & $\%$ \\
\hline 1 & 1166 & 60.4 & 1011 & 42.7 \\
2 & 9760 & 30.3 & 10703 & 33.4 \\
3 & -10976 & -20.5 & -11833 & -22.2 \\
4 & 126 & 77.3 & 139 & 84.8 \\
5 & -82 & -6.9 & -27 & -2.3 \\
\hline
\end{tabular}

Table 8. Difference is area change per class between the CLC and the CCI LC for years 2006 and 2012, in $\mathrm{km}^{2}$ and percentage

Figure 5 and Figure 6 show the CCI LC and the COS for 2015 using the harmonized nomenclature in Table 3 . The main feature resulting from the visual analysis of these figures is, on one hand, the larger mixture between classes 2 and 3 in COS (interconnection between agriculture and forest areas) and a larger dispersion of the urban areas along the country, mainly along the western border.

Table 9 shows the areas obtained per class for both years, Table 10 shows the differences between the two years for each product and Table 11 shows the difference obtained for area change in each class when estimated with the CCI LC and the COS.

The results in Tables 9 and 11 show that the area of the urban regions in the COS are almost the double of the ones represented in the CCI LC. Regarding the change detected between 2010 and 2015 using the CCI LC and the COS (see Table 10), the most relevant result is the increase of class 1 (Artificial surfaces) detected by CCI LC is much larger than the one detected by COS (5467 $\mathrm{km}^{2}$ for CCI LC and $1069 \mathrm{~km}^{2}$ for COS).

\begin{tabular}{|l|c|c|c|c|}
\hline \multirow{2}{*}{ Classes } & \multicolumn{2}{|c|}{2010} & \multicolumn{2}{c|}{2015} \\
\cline { 2 - 5 } & CCI LC & COS & CCI LC & COS \\
\hline 1 & 2226 & 4459 & 2646 & 4541 \\
2 & 32099 & 35678 & 31830 & 34896 \\
3 & 53441 & 47239 & 53287 & 47898 \\
4 & 164 & 326 & 166 & 264 \\
5 & 1182 & 1411 & 1184 & 1514 \\
\hline
\end{tabular}

Table 9. Areas in $\mathrm{km}^{2}$ per class for the CCI LC and the COS for years 2010 and 2015

\begin{tabular}{|l|c|c|c|c|}
\hline \multirow{2}{*}{ Classes } & \multicolumn{2}{|c|}{ CCI LC (2015-2010) } & \multicolumn{2}{c|}{ COS $(2015-2010)$} \\
\cline { 2 - 5 } & $\mathrm{km}^{2}$ & $\%$ & $\mathrm{~km}^{2}$ & $\%$ \\
\hline 1 & 5467 & 19 & 1069 & 2 \\
2 & -3506 & -1 & -10190 & -2 \\
3 & -2012 & 0 & 8582 & 1 \\
4 & 27 & 1 & -807 & -19 \\
5 & 24 & 0 & 1346 & 7 \\
\hline
\end{tabular}

Table 10. Area differences per class between 2015 and 2010 for the CCI LC and the COS, in $\mathrm{km}^{2}$ and percentage

\begin{tabular}{|l|c|c|c|c|}
\hline \multirow{3}{*}{ Classes } & \multicolumn{2}{|c|}{$\begin{array}{c}\text { COS-CCI LC } \\
(2010)\end{array}$} & \multicolumn{2}{c|}{$\begin{array}{c}\text { COS-CCI LC } \\
(2015)\end{array}$} \\
\cline { 2 - 5 } & $\mathrm{km}^{2}$ & $\%$ & $\mathrm{~km}^{2}$ & $\%$ \\
\hline 1 & 2233 & 100.3 & 1895 & 71.6 \\
2 & 3579 & 11.1 & 3066 & 9.6 \\
3 & -6202 & -11.6 & -5389 & -10.1 \\
4 & 162 & 99.1 & 98 & 59.3 \\
5 & 228 & 19.3 & 330 & 27.9 \\
\hline
\end{tabular}

Table 11. Difference is area change per class between the COS and the CCI LC for years 2010 and 2015, in $\mathrm{km}^{2}$ and percentage

\subsection{LC change detection validation for the study areas}

The analysis performed as described in section 2.3.4 for the study areas A and B described in section 2.4 and shown, respectively, in Figures 1 and 2 are presented in the sections below.

3.3.1 Study area A: Figure 7 shows the CCI LC products for 2006, 2010, 2012 and 2015 for study area A, while Figure 8 a) and c) show, respectively, the 2006 and 2012 UA for this study area, and Figure c) and d) show the COS for years 2010 and 2015. Table 12 shows the commission errors (CE), omission errors (OE) and overall accuracy (OA) obtained for study area A, for the 2010 and 2015 CCI LC, considering the COS as reference data, while Table 13 shows the results obtained for 2006 and 2012 considering the UA of the corresponding years as reference data.

\begin{tabular}{|l|c|c|c|c|}
\hline \multirow{2}{*}{ Classes } & \multicolumn{2}{|c|}{ CCI LC 2010 } & \multicolumn{2}{c|}{ CCI LC 2015 } \\
\cline { 2 - 5 } & CE & OE & CE & OE \\
\hline 1 & 25.7 & 58.3 & 27.8 & 42.5 \\
2 & 41.2 & 17.7 & 38.6 & 20.4 \\
3 & 26.2 & 31.9 & 23.9 & 32.4 \\
4 & 100.0 & 100.0 & 100.0 & 100.0 \\
5 & 50.0 & 77.5 & 43.8 & 77.5 \\
\hline OA & \multicolumn{2}{|c|}{66.0} & \multicolumn{2}{c|}{68.3} \\
\hline
\end{tabular}

Table 12. Commission errors (CE), Omission errors (OE) and Overall Accuracy (OA) of the 2010 and 2015 CCI LC for study area $\mathrm{A}$, obtained considering the $\mathrm{COS}$ as reference data.

\begin{tabular}{|l|c|c|c|c|}
\hline \multirow{2}{*}{ Classes } & \multicolumn{2}{|c|}{ CCI LC 2006 } & \multicolumn{2}{c|}{ CCI LC 2012 } \\
\cline { 2 - 5 } & CE & OE & CE & OE \\
\hline 1 & 15.1 & 64.4 & 15.7 & 57.0 \\
2 & 33.7 & 24.4 & 36.6 & 21.1 \\
3 & 39.0 & 17.9 & 33.7 & 23.9 \\
4 & 100.0 & 100.0 & 100.0 & 100.0 \\
5 & 50.0 & 75.7 & 50.0 & 75.7 \\
\hline OA & \multicolumn{2}{|c|}{66.2} & \multicolumn{2}{c|}{67.2} \\
\hline
\end{tabular}

Table 13. Commission errors (CE), Omission errors (OE) and Overall Accuracy (OA) of the 2006 and 2012 CCI LC for study area $\mathrm{A}$, obtained considering the UA as reference data. 

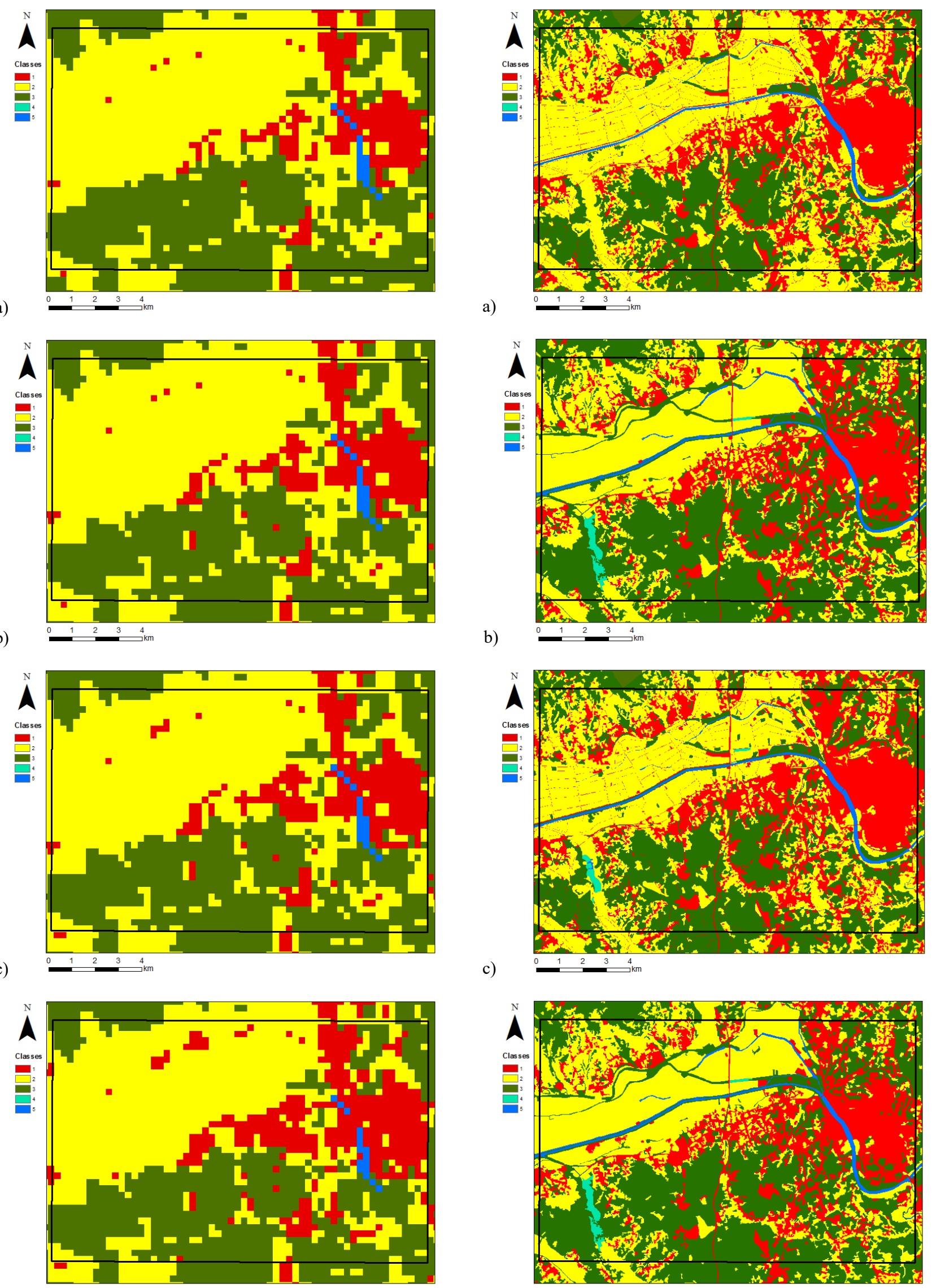

d)

c)

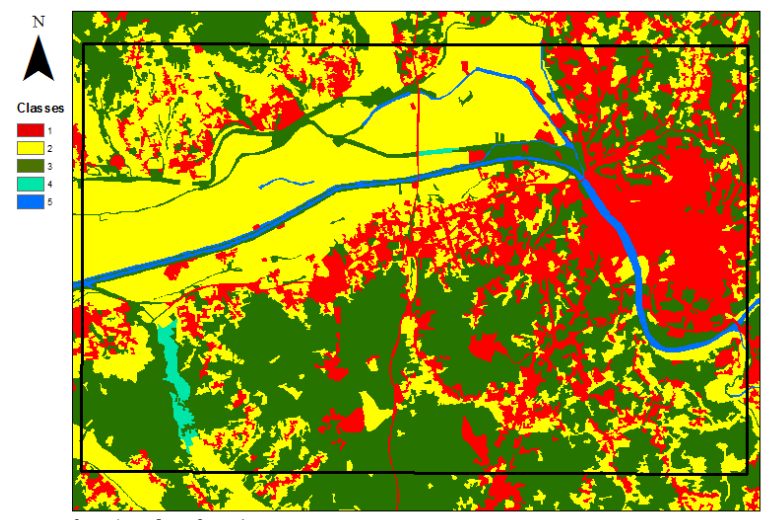

Figure 7. CCI LC for study area A: a) 2006, b) 2010, c) 2012, d) 2015.

Figure 8. Study area A: a) UA 2006, b) COS 2010, c) UA 2012, d) $\operatorname{COS} 2015$. 


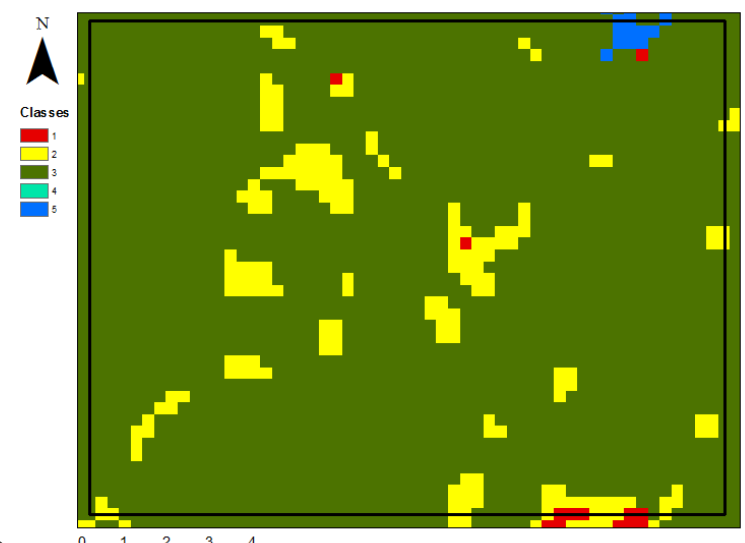

a)

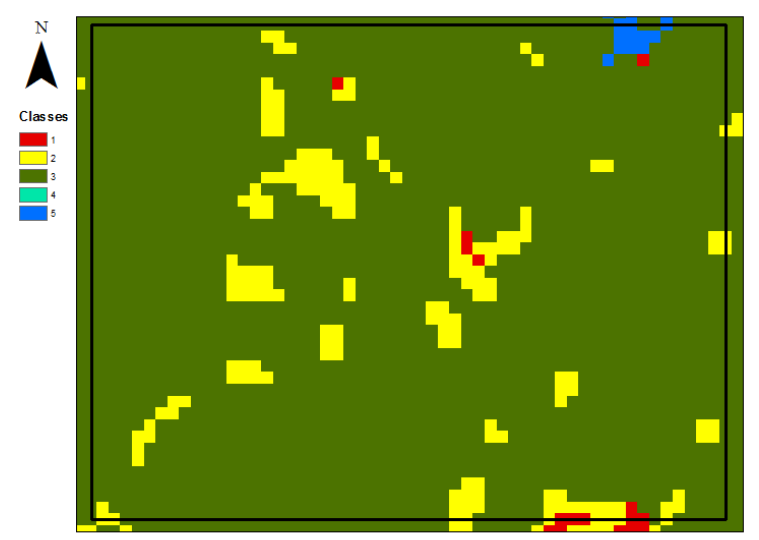

b)

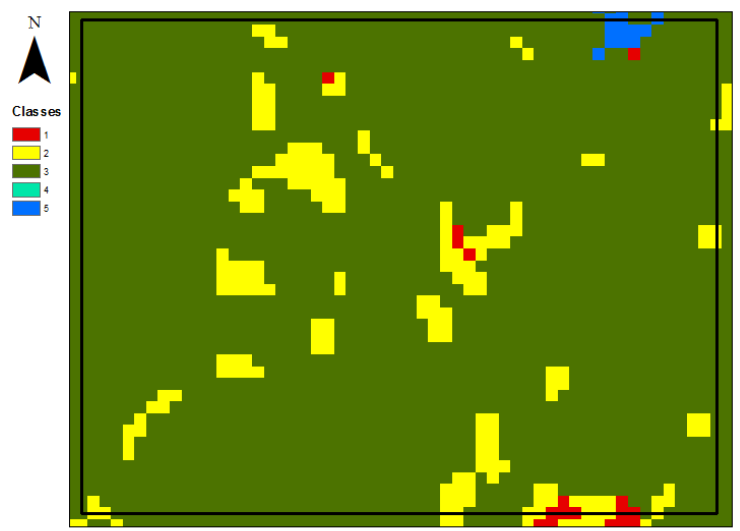

c)

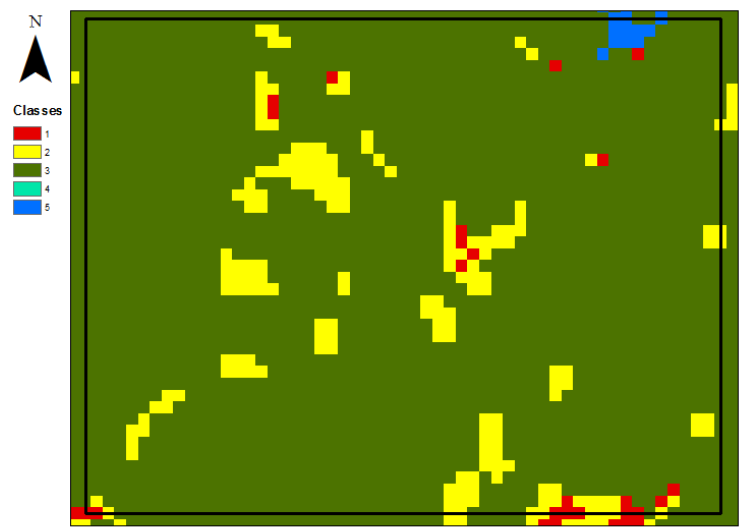

d)

Figure 9. CCI LC for study area B: a) 2006, b) 2010, c) 2012, d) 2015.

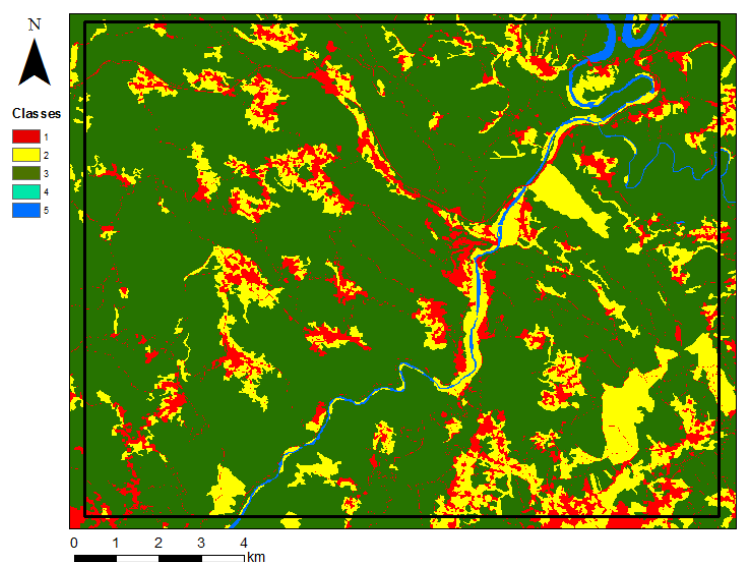

a)

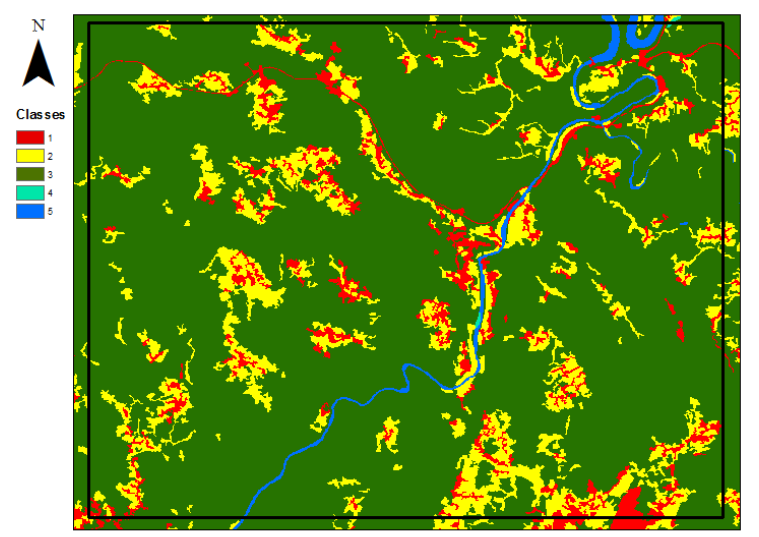

b)

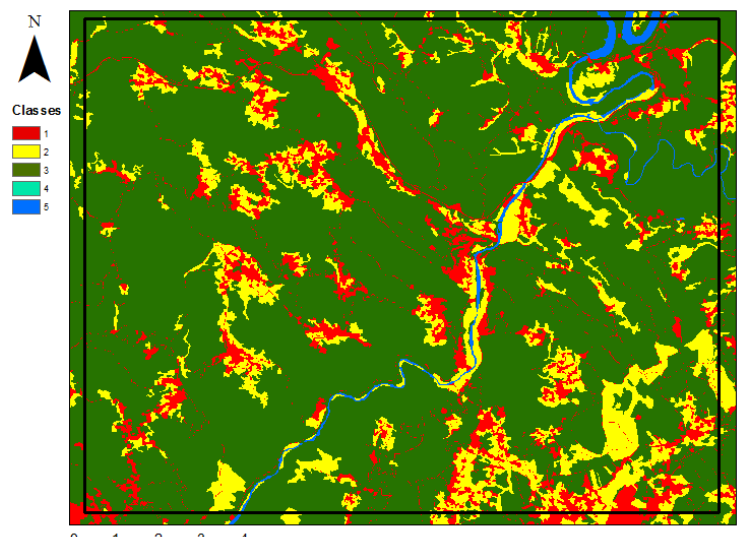

c)

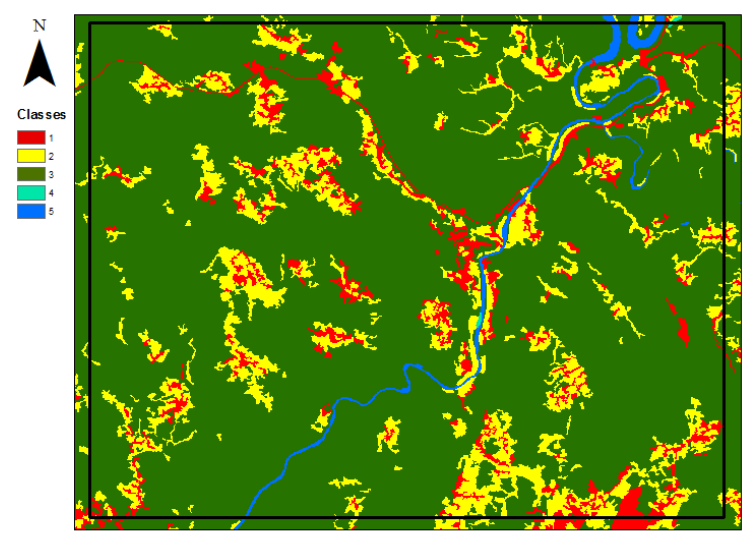

d)

Figure 10. Study area B: a) UA 2006, b) COS 2010, c) UA 2012, d) COS 2015. 
It can be seen that the results are similar in terms of accuracy, with OAs between $66.0 \%$ and $68.3 \%$. Class 4 has both $\mathrm{OE}$ and $\mathrm{CE}$ of $100 \%$, because in this study area no pixel was assigned to this class in the CCI LC, while there were a few small areas assigned to it in both COS and UA. In addition, the classes showing larger CE are classes 5 and 2, except for CCI LC of 2006, where the CE error of class 3 is 5.3\% larger than for class 2. Large OE can be observed for classes 5 and 1.

3.3.2 Study area B: Figure 8 shows the CCI LC products for 2006, 2010, 2012 and 2015 for study area B, while Figure 9 a) and c) show, respectively, the 2006 and 2012 UA for this study area, and Figure c) and d) show the COS for years 2010 and 2015. Table 14 shows the CE, OE and OA obtained for study area B for CCI LC 2010 and 2015 considering COS as reference data, while Table 15 shows the results obtained for 2006 and 2012 considering UA of the corresponding years as reference data.

\begin{tabular}{|l|c|c|c|c|}
\hline \multirow{2}{*}{ Classes } & \multicolumn{2}{|c|}{ CCI LC 2010 } & \multicolumn{2}{c|}{ CCI LC 2015 } \\
\cline { 2 - 5 } & CE & OE & CE & OE \\
\hline 1 & 27.3 & 93.5 & 38.1 & 89.6 \\
2 & 47.6 & 68.6 & 46.5 & 67.4 \\
3 & 13.6 & 2.0 & 13.4 & 2.2 \\
4 & 100.0 & 100.0 & 100.0 & 100.0 \\
5 & 25.0 & 78.6 & 25.0 & 79.3 \\
\hline OA & \multicolumn{2}{|c|}{83.7} & \multicolumn{2}{c|}{83.9} \\
\hline
\end{tabular}

Table 14. Commission errors (CE), Omission errors (OE) and Overall Accuracy (OA) of the 2010 and 2015 CCI LC for study area $\mathrm{B}$, obtained considering the $\mathrm{COS}$ as reference data.

\begin{tabular}{|l|c|c|c|c|}
\hline \multirow{2}{*}{ Classes } & \multicolumn{2}{|c|}{ CCI LC 2006 } & \multicolumn{2}{c|}{ CCI LC 2012 } \\
\cline { 2 - 5 } & CE & OE & CE & OE \\
\hline 1 & 12.5 & 96.8 & 16.7 & 95.7 \\
2 & 62.4 & 78.5 & 63.7 & 76.6 \\
3 & 18.8 & 1.9 & 17.9 & 2.2 \\
4 & 100.0 & 100.0 & 100.0 & 100.0 \\
5 & 25.0 & 73.9 & 25.0 & 73.9 \\
\hline OA & \multicolumn{2}{|c|}{77.9} & \multicolumn{2}{|c|}{78.5} \\
\hline
\end{tabular}

Table 15. Commission errors (CE), Omission errors (OE) and Overall Accuracy (OA) of the 2006 and 2012 CCI LC for study area $\mathrm{B}$, obtained considering $\mathrm{UA}$ as reference data.

The results show a similar behaviour for study area $\mathrm{B}$, where the main difference is that $\mathrm{CE}$ are much larger for class 2 while $\mathrm{OE}$ are almost non-existent for class 3 but are much larger for all other classes except class 4 , which is $100 \%$, for the same reasons as in study area A.

\section{DISCUSSION AND CONCLUSIONS}

There is general consensus among the LC products, i.e., most of the changes that have occurred are in class 1, i.e., expansion of urbanized areas as a land cover transition from agriculture and forested/natural areas. When the CCI LC is compared with other products, there are some notable differences, which are mainly found in classes that occupy small areas. These classes are underestimated in CCI LC due to the larger spatial resolution of this product. For example, the change in class 1 is larger in CCI LC compared to CLC while the direction of change is different for class 2, i.e., CCI LC shows a decrease while CLC shows an increase, but the relative values are small. In contrast, when CCI LC is compared to COS, the direction of change is the same for classes 1 and 2, i.e. increasing urbanization and decreasing agriculture although the amount of urbanization is much higher in CCI LC compared to COS. However, class 3 (forests and (semi-)natural areas) decreases in the CCI LC but increases in the COS although the overall amount is $1 \%$ or less. Looking at the absolute values, it is clear that CCI LC overestimates class 3 by $11-13 \%$ when compared with the COS, which is by far the largest class in Portugal.

The analysis performed in this paper compared CCI LC with existing products using a systematic sample of points corresponding to the centroids of the CCI LC pixels. The comparison with the COS enables to achieve a good initial perspective of the CCI LC quality because COS has a high level of detail and accuracy. However, even though COS is available for the whole country, only version of 2007, 2010 and 2015 exist. UA provides comparable results, but it is only available for a few regions around urban areas for the years 2006 and 2012. Therefore, to validate the CCI LC products for additional years and the LC change for consecutive years a different validation approach needs to be used, using a sampling protocol and interpretation of very high-resolution imagery (when available for the years under analysis). This will be undertaken as part of future work.

\section{ACKNOWLEDGEMENTS}

The study has been partly supported by the Portuguese Foundation for Science and Technology (FCT) under project grant UID/MULTI/00308/2019.

\section{REFERENCES}

Buettner G (2014) CORINE land cover and land cover change products. In: Manakos I, Braun M (eds) Land use and land cover mapping in Europe: practices \& trends. Springer, Dordrecht, pp 55-74

Caetano M, Igreja C, Marcelino F (2018) Especificações Técnicas da Carta de Uso e Ocupação do Solo (COS) de Portugal Continental para 1995, 2007, 2010 e 2015. Direção-Geral do Território

EEA (2011) Mapping guide for a European Urban Atlas. Available from: http://www.eea.europa.eu/data-andmaps/data/urban-atlas [Accessed 15 April 2014].

Santoro M, Kirches G, Wevers J, et al (2017) Land Cover CCI. Product User Guide Version 2.0. Availlable at: http://maps.elie.ucl.ac.be/CCI/viewer/download/ESACCI-LCPh2-PUGv2_2.0.pdf

Revised April 2019 